\title{
KAJIAN TEOLOGI MORAL TERHADAP FASHION SEBAGAI ISU BUDAYA POPULER
}

\author{
Stella Y.E. Pattipeilohy dan Yahya Wijaya \\ Fakultas Teologi Universitas Kristen Duta Wacana \\ Email: exlentyapattipeilohy@yahoo.com
}

\begin{abstract}
The focus of this study is fashion as an issue in the discourses on popular culture. Fashion in this case is considered not merely a matter of basic human needs (clothing, eating, and living), but a meaningful cultural "text" and a "sign" of identity politics, moral value change, and spiritual preference. The moral theological response suggested here is the ideology criticism approach promoting the values of authenticity and simplicity, starting from the fashion practice of faithful communities.
\end{abstract}

Keywords: Authenticity; Fashion; Ideology criticism; Moral theology; Popular culture.

\section{ABSTRAK}

Fokus kajian ini adalah fashion sebagai suatu isu dalam diskursus budaya populer. Fashion dalam hal ini bukan sekadar suatu kebutuhan dasar manusia (sandang, pangan, dan papan), melainkan sebuah "teks" budaya yang sarat makna dan suatu "tanda" bagi politik identitas, perubahan nilainilai moral, dan preferensi spiritual. Respon teologi moral yang disarankan di sini adalah pendekatan kritik ideologis yang mengusung nilai-nilai keautentikan dan kesederhanaan yang diawali dari praktik fashion komunitas yang taat.

Kata kunci: Budaya populer; Fashion; Keautentikan; Kritik ideologi; Teologi moral. 


\section{PENGANTAR}

Judul tulisan ini diinspirasi oleh penampilan Sr. Cristina, seorang rohaniwan Katolik diajang sebuah pencarian bakat yang dibilang mewakili dunia sekuler (Purwatma, 2016:5773). "Singing nun Cristina Scuccia becomes internet star after The Voice audition", begitulah judul berita sebuah situs internet The Guardian tanggal 21 Maret 2014. Berita ini adalah tentang suster, Sr. Cristina, yang tampil memukau dan mengejutkan para juri dalam audisi The Voice of Italy tanggal 19 Maret 2014. Penampilannya dipandang mewakili suatu fungsi komunikatif. Busana, pakaian, kostum, salib, dan dandanan seorang religius perempuan dari Sr. Cristina adalah bentuk komunikasi artifaktual (artifactual communication). Komunikasi artifaktual dapat didefinisikan sebagai komunikasi yang berlangsung melalui busana dan penataan berbagai artefak, misalnya dandanan, aksesori, kancing baju, salib, kerudung, penutup muka, atau perkakas di rumah dan penataannya, ataupun dekorasi di sebuah ruang kerja. Fashion, pakaian atau busana dengan aksesorinya menyampaikan pesanpesan non-verbal dan termasuk ke dalam komunikasi non-verbal (Ibrahim dalam Barnard, 2001). Tidak hanya itu, pernyataan verbal Sr. Cristina pun menarik. Saat ia ditanya apa kira-kira pendapat Paus Fransiscus tentang penampilannya, ia mengatakan, "Saya tidak tahu, saya sedang menunggu telepon dari Paus, karena beliau minta kami untuk pergi keluar, untuk menjalankan evangelisasi, untuk mengatakan bahwa Allah tidak mengambil tetapi memberi". Dalam catatan The Guardian, dua hari setelah video sang suster diunggah ke media sosial, video tersebut sudah ditonton lebih dari tiga juta penonton di youtube.

Penampilan Sr. Cristina dalam audisi The Voice of Italy merupakan bagian dari melaksanakan anjuran "Bapak Suci" untuk pergi ke lorong-lorong kota dan mewartakan Injil. Secara khusus, media sosial termasuk internet merupakan tantangan baru bagi gereja untuk mewartakan Injil. Media sosial menjadi bagian yang tidak terpisah dari pembentuk gaya dan fashion seseorang termasuk para rohaniwan dan biarawan seperti Sr. Christina. Ia mewakili "net generation", yaitu generasi masa depan (next generation) karena diasuh dan dibesarkan dalam lingkungan budaya baru media digital, generasi jaringan (net generation) yang melek media dan tidak mau kehilangan "gaya hidup" (lifestyle) dari kebudayaan populer yang sedang menerjang deras. Ia mewakili "gerakan gaya hidup" (lifestyle movement) (Ibrahim, 2011:239-240), melalui fashion dan penampilannya di ruang publik, menegaskan identitas personal sekaligus komunal, menebar wacana, dan sekaligus menantang dialog melalui kehadirannya.

Tulisan ini bermaksud menjelaskan dan menganalisis dunia gaya dan fashion yang sudah menjadi bagian dari selera pasar yang digerakkan oleh media sosial. Analisis tersebut akan ditindaklanjuti dengan refleksi teologis dengan menggunakan pendekatan teologi moral yang menggunakan perspektif etis-teologis sebagai dasarnya. Pertanyaanpertanyaan kunci adalah, apakah fashion dalam hal ini pakaian menunjukkan siapa identitas diri ini atau pakaian justru menyembunyikan identitas diri tersebut yang sebenarnya dan apakah dalam fashion dan pakaian tersusun relasi ideologi. Selain itu, secara teologis akan dikaji di mana Allah dalam gempita fashion. Tampaknya fashion menjadi bagian yang melekat di dalam diri setiap orang (termasuk kaum rohaniwan), yang membuatnya menjadi bagian dari dunia sosialnya sekaligus dirinya tidak dapat lepas dari pengaruh selera yang diciptakan oleh pasar. Kalau hal ini tidak dapat dielakkan, maka bagaimana sikap etis-teologis yang tepat terhadap gempuran dunia fashion yang dahsyat itu.

\section{PEMBAHASAN \\ Fashion dalam Dunia Simulakra}

Dunia hari ini sering dinamai sebagai era postmodern. Diskursus postmodern membedakan antara postmodernitas dan postmodernisme (Horell dalam Groome dan Horell, 2003:82-83; Scheuerer, 2001:6970; Sugiharto, 1997). Postmodernitas adalah praksis sosial yang menunjuk pada situasi dan tata sosial produk teknologi informasi, globalisasi, fragmentasi gaya hidup (fashion), 
konsumerisme, deregulasi pasar uang dan sarana publik, usangnya negara bangsa dan penggalian kembali inspirasi-inspirasi tradisi. Sementara itu, postmodernisme adalah dimensi teoritis tentang kritik-kritik filosofis atas world view, epistemologi, dan ideologiideologi modern. Kalau postmodernitas lebih dilihat sebagai praksis sosial dan budaya dalam perubahan yang sedang terjadi, maka postmodernisme adalah sebuah gerakan intelektual untuk menjelaskan perubahan sosial-budaya dalam arti luas yang sekarang sedang terjadi. Walaupun antara keduanya sering bercampur baur, dalam tulisan ini titik tekan akan diberikan pada postmodernitas sebagai fenomena sosial-budaya di mana budaya populer menjadi bagian yang melekat di dalamnya.

Ciri-ciri postmodernitas dan kritik terhadapnya dijelaskan oleh Dominic Strinati (Strinati, 2004:211-216; Shields, 2011:21-24). Pertama, postmodernitas menandai lahirnya suatu tatanan sosial baru, di mana kekuatan media dan budaya populer mengatur dan membentuk segala macam hubungan sosial. Budaya populer maupun citra media semakin banyak mendominasi rasa realitas dan mendefinisikan diri tersebut. Media khususnya, memainkan peran dalam mengonstruksi rasa ini akan realitas sosial maupun rasa tersebut sebagai bagian dari realitas. Bidang konsumsi apa yang dibeli akan menentukan apa yang dibeli, dan hal ini dipengaruhi oleh budaya populer. Kedua, dalam budaya postmodern, tampilan permukaan dan gaya menjadi lebih penting. Yang dipentingkan adalah mengonsumsi citra maupun tanda itu sendiri, bukan manfaatnya atau nilai-nilainya. Dalam budaya popular bahwa yang tampak mendominasi adalah apa yang dipermukaan dan gaya yang ditampilkan serta sifat mainmain dan senda gurau, dengan mengorbankan isi, substansi, dan makna. Sedangkan sifatsifat artistik, integritas, keseriusan, otentisitas, kedalaman intelektual, dan narasi yang kuat cenderung diabaikan. Bahkan, gambaran dari realitas maya (virtual reality) dianggap riil ketimbang realitas itu sendiri. Ketiga, jika gaya mendahului isi, maka budaya massa pada akhirnya akan menundukkan budaya tinggi (budaya seni, estetik, dan refleksi). Hal ini dikarenakan budaya populer postmodern menolak menghargai pretensi maupun kekhasan seni. Keunikan dan citra artistik lukisan Mona Lisa dihancurkan oleh reproduksi masal melalui mesin cetak dan malahan menjadi sebuah lelucon. Keempat, gagasan-gagasan yang sebelumnya koheren dan tunggal mengenai ruang dan waktu mulai ditumbangkan, terdistorsi, dan diragukan. Oleh karena itu, budaya populer postmodern tidak mementingkan rasa koheren ruang atau waktu. Hal ini merupakan hasil dari arus informasi tanpa batas dan realitas pun cepat berubahubah (realitas hiper) serta cepat berpindah, akibatnya ruang dan waktu semakin tidak koheren. Kelima, dunia postmodern metanarasi (meta-narrative) sedang ditumbangkan. Semua metanarasi, termasuk agama, terbuka untuk dikritik dan menjadi kurang penting. Termasuk postmodernitas menolak klaim teori atau pengetahuan mutlak. Sifat budaya populer postmodern yang beragam, ikonoklastik, referensial, dan seperti kolase jelas mendapatkan inspirasi dari tumbangnya metanarasi. Hal yang paling penting dari sekian ciri postmodernitas tersebut adalah budaya populer postmodern membungkus berbagai perubahan radikal melalui peranan media sosial yang menghapuskan pembedaan antara citraan dan realitas di mana citraan dianggap lebih riil daripada realitas.

Makin tidak pentingnya perbedaan antara citra dan realitas membuat budaya populer postmodern menjadi mesin pencipta "kebudayaan kemasan". Di dalam budaya kemasan, seringkali citra lebih penting dari realitas, dan bahkan citra menjadi "realitas baru" (realitas citra) (Ibrahim, 2011:239-240; Ibrahim dalam Chaney, 2002:18-19). Bahkan, tak jarang pula kita lebih mempercayai "realitas baru" atau citra tersebut. Karena citra dianggap "lebih riil" daripada "yang riil" (benda konkret yang dapat dipegang). "It's the real thing!" Justru lebih mempercayai imaji karena ia senantiasa menjadi bayangan dalam imajinasi. Manakala citra mendominasi imajinasi tersebut, maka bukan mustahil pula ia menjadi lebih 
penting daripada makna. Setidaknya itulah yang diprihatinkan oleh Gerrit Singgih dalam tulisannya bahwa manusia kehilangan makna karena dunia maya dianggap sebagai realitas atau yang riil (Singgih, 2017:1-6). Akhirnya, citralah yang lambat-laun mempengaruhi nilai-nilai dalam memandang sesuatu, semua terobsesi dengan citra, citra mendominasi persepsi, bahkan masuk ke dalam realitas menjadi tidaklah penting.

Dunia hari ini mengalami apa yang disebut oleh filsuf Prancis, Jean Baudrillard sebagai simulacrum, yaitu kemampuan membunuh gambar, membunuh yang riil, membunuh modelnya itu sendiri seperti halnya ikon yang bisa menggantikan "yang Ilahi" (Baudrillard, 1992: 166-184; Haryatmoko, 2016:79; Marsh dan Roberts, 2012:144; Chaney, 2002:106). Sebagai contoh, seorang gadis kecil berumur lima tahun ketika di supermarket meminta ibunya untuk membelikan Laurier (merek pembalut perempuan). Tentu saja ibunya terkejut. Lalu dijelaskanlah oleh ibunya bahwa barang itu diperuntukkan bagi perempuan dewasa. Akan tetapi, gadis kecil itu tidak mau mengerti dan menangis tetap meminta barang tersebut. Dengan sabar, ibu itu menanyakan kepada putrinya mau digunakan untuk apa pembalut tersebut. Si anak menjawab dengan yakin: "Saya ingin bisa berenang, saya ingin bisa naik kuda". Ibu itu baru sadar bahwa putrinya sebelum berangkat belanja bersamanya menyaksikan iklan di TV dan di situ ditayangkan iklan Laurier yang mengatakan: "Dengan Laurier, Anda bisa berenang, bisa naik kuda" (Haryatmoko, 2016:65). Cerita ini sama halnya dengan banyak orang rela membeli rumah yang masih berupa maquette (denah) dan dengan semangat menjelaskan kepada anak-anaknya di mana kamar masing-masing, dapur, ruang makan, garasi atau tempat belajar. Padahal rumah itu baru akan selesai satu tahun lagi. Banyak perempuan sosialita bersedia membeli tas Hermes yang harganya paling murah 7.500 Euro meskipun harus inden satu tahun sebelumnya. Kecenderungan mengonsumsi yang riil melalui tanda, hanya baru memesan dengan uang muka sudah merupakan kenikmatan yang diantisipasi (Baudrillard, 1992:29-
56; Haryatmoko, 2016:65-66). Jadi, sikap seperti itu yang dimaksud dengan "tanda dianggap sebagai realitas itu sendiri dan tanda riil dianggap sebagai yang riil itu sendiri". Itulah dunia simulacrum.

Postmodernitas membentuk budaya popular dan pertanyaannya adalah apakah itu budaya populer. Budaya populer dapat dimaknai sebagai sekumpulan artefak yang ada misalnya film, kaset, fashion, pakaian, acara $\mathrm{TV}$, alat transportasi, dan sebagainya. Selain artefak, budaya populer menunjuk pula pada proses sosial sebagaimana yang dipraktikkan oleh masyarakat dan tidak pernah sama pada masyarakat lainnya (Strinati, 2004). Definisi yang cukup luas tersebut menyentuh fashion sebagai bagian inheren dari budaya populer. Secara etimologis, kata "fashion" berasal dari bahasa Latin, factio, yang artinya membuat atau melakukan, facere yang artinya juga membuat atau melakukan. Untuk itu, arti asli fashion mengacu pada kegiatan, fashion merupakan sesuatu yang dilakukan seseorang. Arti asli fashion pun mengacu pada ide tentang fetish atau objek fetish yang artinya memuja suatu barang atau harga melampaui asas manfaatnya (Barnard, 2001:11-12; Strinati, 2004:52). Harga tiket konser dianggap lebih penting daripada konser itu sendiri. Barang-barang fashion dan pakaian adalah komoditas yang paling di-fetishkan. Barang-barang yang dikenakan orang memberi bentuk dan warna pada pembedaan dan ketimpangan sosial. Setiap hari seseorang memutuskan tentang peran dan status sosial orang yang dijumpai berdasarkan apa yang mereka kenakan. Bila memperlakukan pakaian yang dikenakan sebagai "hieroglif sosial" (Barnard, 2001:12) yang menyembunyikan atau bahkan mengomunikasikan posisi sosial pemakainya.

Umberto Uco menjelaskan bahwa "aku berbicara lewat pakaianku" (I speak through my cloth). Pakaian yang kita kenakan membuat pernyataan tentang diri sendiri (self-revelation, self-identity). Sekalipun mungkin bukan tipe orang yang peduli pada penampilan atau fashion, tetapi orang yang berinteraksi dengan orang lain tetap akan menafsirkan penampilan tersebut dengan pemahaman bahwa ini 
sedang menghadirkan sebuah pesan. Pakaian yang dipakai menampilkan pelbagai fungsi (Detweiler dan Taylor, 2003: 222, 224, 226; Ibrahim dalam Barnard, 2001; Hoed, 2008:163164). Sebagai bentuk komunikasi, pertama, pakaian berfungsi melindungi diri dari cuaca atau cidera; kedua, pakaian memainkan fungsi kesopanan (modesty function) karena membantu untuk menyembunyikan bagianbagian tertentu dari tubuh; dan ketiga, pakaian berfungsi sebagai pajangan budaya (cultural display) karena ia mengomunikasikan afiliasi budayanya. Di sini, pakaian dapat menunjukkan identitas nasional dan kultural si pemakainya. Secara keseluruhan, ketiga fungsi itu hendak mengatakan bahwa orang membuat kesimpulan tentang siapa diri ini melalui apa yang dipakai (Detweiler dan Taylor, 2003:226). Pakaian akan memengaruhi pikiran orang tentang diri ini dan bagaimana mereka bersikap padanya. Kelas sosial, keseriusan atau kesantaian, sikap (konservatif atau liberal), afiliasi politik (Golkar atau PDI-P), keglamoran atau keeleganan, dan sense of style personal akan dinilai sebagian dari cara dirinya berpakaian.

Paul Ricoeur pernah mengatakan bahwa "...the symbol gives rise to thought". Artinya bahwa simbol menimbulkan pemikiran (Ricoeur, 1970:38). Ketika simbol menimbulkan pemikiran, bersamaan itu tercipta tugas untuk berpikir, menafsirkan pesan, dan memberikannya makna melalui refleksi. Simbol berupa "aksesori" yang kita kenakan mengomunikasikan pesan tentang Salib, kerudung, dan pakaian seperti yang dikenakan Sr. Cristina jelas adalah contoh fashion dan perhiasan yang mengomunikasikan pesan yang istimewa tentang asal-usulnya dari kaum religius. Cincin pertunangan atau perkawinan mengomunikasikan pesan tentang ikatan yang sudah dijalin. Jaket almamater dan kaos partai juga menyampaikan pesan tertentu tentang latar belakang dan afiliasi politik. Jam rolex adalah pesan dari kelas sosial seperti apa dirinya berasal. Laki-laki dengan anting-anting dan bertindik di bibir, serta perempuan dengan tato di tangan dan kakinya akan memberi pesan tertentu daripada mereka yang tidak menggunakannya. Demikian pula gaya potong rambut dan menyisir rambut memberikan pesan tentang cita rasa, hasrat, dan aliran hidup yang dipilih.

Simbol sesungguhnya tidak hanya membangkitkan pemikiran, tetapi seperti fenomena Sr. Cristina, juga menimbulkan keterkejutan yang di satu sisi dihujat, tetapi di sisi lain memberikan kesadaran dan refleksi. Inilah yang dapat dilihat melalui penampilan fashionate Lady Gaga dalam video klipnya, Judas (Adhi dalam Rukiyanto, 2012:430-431; Detweiler dan Taylor, 2003:230). Dengan gaya satire ia menampilkan dirinya sebagai Maria Magdalena. Dalam video klip tersebut, melalui fashion dan pakaiannya, Lady Gaga memerankan Maria Magdalena yang memimpin para murid Yesus bersepeda motor ke kota dan bertemu dengan Yesus. Karakter-karakter Alkitab yang "dipinjamnya", membuat Lady Gaga menuai protes dan hujatan dari kalangan Katolik konservatif. Mereka menganggap, Lady Gaga sengaja menyembunyikan penampilannya dengan berada dibalik sosok panutan Kristiani. Akan tetapi, secara reflektif, penampilan Lady Gaga mewakili arus besar generasi masa kini (generasi next/net) dengan identitas otonomnya, yang menerobos sekat-sekat kepantasan, kesopanan berpakaian, dan memberontak pada nilai-nilai yang dianggap sakral yang utamanya diusung oleh agama. Lady Gaga menempatkan dirinya dalam post (modern) terhadap segala nilai-nilai konservatisme. Identitas performatif (hybrid) yang ditampilkan Lady Gaga merupakan hasil langsung dari arus globalisasi berupa "gerakan gaya hidup" (lifestyle movement) (Ibrahim, 2011:316) yang secara langsung atau tidak turut mengubah realitas.

\section{Fashion sebagai Komunikasi dan Relasi Ideologis}

Pada abad ke-19, pakaian dirancang untuk menyembunyikan tubuh. Pandangan ini masih dapat dirasakan hingga paruh pertama abad ke-20. Simbolisasinya dapat dilihat pada gaun penobatan Ratu Elizabeth II tahun 1951 atau empire cut dress (baju potong kekaisaran) di Prancis yang dirancang sebagai simbol 
kontinuitas, tradisional, dan ketertutupan. Akan tetapi, semua berubah ketika dua tahun setelahnya, tahun 1953, muncul busana "lini tulip" Dior dan dilanjutkan miniskirts tahun 1960, yang mengumumkan datangnya musim baru dan berfungsi sebagai simbol diskontinuitas dan perubahan (Detweiler dan Taylor, 2003:225; Barnard, 2001:20-21). Jubah Ratu dan empire cut dress dimaksudkan untuk menekankan kontinuitas, yaitu kontinuitas monarki dan kerajaan Inggris. Busana tersebut selain menggambarkan kehormatan dengan simbolnya serba tertutup, juga berkaitan dengan pemeliharaan status quo. Sebaliknya, busana Dior dan miniskirts dimaksudkan untuk menunjukkan pada diskontinuitas dan perubahan model fashion atau gaun yang makin terbuka dan menolak kemapanan. Kedua model gaun tersebut dan fungsinya dapat dipakai untuk memahami zaman yang berbeda. Gaun Ratu mewakili anti-fashion yang lamban perubahannya dan dimaksudkan untuk memelihara status quo bahkan ketertutupan budaya. Sebaliknya, gaun Dior dan miniskirts mewakili dunia fashion yang berubah secara cepat dalam waktu dan menandai bangkitnya budaya konsumen dan revolusi seksual (sexual revolution), dan menegaskan pula pergeseran "gaya hidup" menjadi "hidup bergaya" (Ibrahim, 2011:303; Detweiler dan Taylor, 2003:225).

Budaya konsumen yang memanjakan konsumen untuk berbuat apa saja adalah produk langsung dari arus globalisasi yang melanda dunia. Globalisasi mendapat wujud paling jelas dalam persaingan kapitalisme melalui persaingan merebut sumberdaya dan pasar. Kapitalisme global adalah panggung tempat arena konstruksi kebudayaan dimainkan, tempat rekayasa selera dikemas, dan tempat impian ditaburkan. Kapitalisme global juga tampil sebagai panggung tempat terjadi pertarungan sub-kultur dan perburuan identitas yang tanpa akhir. Globalisasi membawa ancaman tersendiri karena menyuguhkan ruang tegangan budaya (cultural tension) yang ditandai oleh kebangkitan tribalisme yang mematikan (lethal), yang melawan semua yang berbau global, termasuk terjadinya perubahan nilai-nilai etik-moral keagamaan (Schreiter, 1998:44-45). Di saat dunia Barat mengampanyekan keterbukaan yang diwakili oleh tren global model fashion yang terbuka dan vulgar hingga telanjang (nude), dunia Islam, utamanya dari kebudayaan lokal penentang Amerikanisme, menampilkan model fashion serba tertutup (burqa) (Baran dan Tuohy, 2011:143). Wajar orang kemudian menoleh pada tesis Samuel Huntington soal "benturan peradaban" (clash of civilization): global-lokal, Barat-Islam.

Salah satu perubahan nilai akibat dari arus globalisasi menyasar pada bagaimana barang produksi memanjakan konsumen (Detweiler dan Taylor, 2003:226-228,236-237; Chaney, 2002:56-59). Filsuf Michel Foucault sudah membayangkan suatu dunia (dalam hal ini dunia konsumen) di mana orang akan menjadi semakin terobsesi dengan seks sampai ia menjadi mode utama wacana. Di abad budaya konsumen, tubuh dimanjakan dan dinyatakan sebagai wahana kenikmatan (a vehicle of pleasure). Tubuh bahkan menjadi bidang komunikasi non-verbal terbesar manusia. Dalam budaya konsumen, dimungkinkan tanpa rasa malu memajang tubuh manusia. Fenomena tindik, tato, melukis tubuh (body painting) hingga modifikasi tubuh (body modification) pun berkembang sebagai bagian dari merayakan kebebasan tubuh sebagai milik yang masih dapat dikuasai. Pakaian dirancang untuk merayakan bentuk tubuh manusia yang "alami". Citra tentang keindahan tubuh, terbuka secara seksual, kekacauan gender (lakilaki feminine-androgini: anting, syal, dan lejing) dan terkait secara hedonisme, waktu luang dan display tubuh, menekankan pentingnya penampilan dan keelokan dalam pandangan visual.

Fashion tidak dapat dipisahkan dari relasinya dengan ideologi. Dalam penjelasan etimologi fashion, dimensi ideologisnya cukup jelas. Kata "fashion" berasal dari bahasa Latin, factio, dan dari kata inilah dimemperoleh kata "faksi", yang memiliki arti politis (Barnard, 2001:11,55; Storey, 2010:2-3). Kata "faksi" mengacu pada konflik di antara kelompok-kelompok dan pada penguasaan 
serta pelaksanaan kekuasaan oleh kelompokkelompok yang berbeda. Hal ini berarti bahwa fashion sebagai fenomena komunikatif dan kultural tidak pernah netral dan mengusung ideologi tertentu. Fashion dan pakaian mungkin merupakan cara paling signifikan yang bisa digunakan dalam mengonstruksi, mengalami, dan memahami relasi ideologis (sosialpolitis) di kalangan manusia. Barang-barang yang dikenakan orang memberi bentuk dan warna pada pembedaan dan ketimpangan sosial. Fashion dan pakaian juga merupakan praktik penandaan, yang di dalamnya terjadi pembangkitan makna, yang memproduksi dan mereproduksi kelompok-kelompok budaya tersebut sejalan dengan posisinya di dalam kekuasaan. Pakaian dapat saja netral dan dikenakan oleh pemakainya dengan motif tulus, tetapi fungsi yang dijalankannya tidaklah netral atau tulus. Fashion dan pakaian ibarat pagar atau jembatan, yang satu "diferensiasi" dan yang lain "sosialisasi" (Barnard, 2001:56). Pagar merupakan pembatas wilayah yang membuat orang terpisahkan dan memastikan bahwa perbedaan-perbedaan itu tetaplah ada. Sementara itu, jembatan digunakan untuk memadukan atau menghubungkan manusia untuk bertemu, bergabung, dan berbagi identitas. Barang-barang fashion dan pakaian melukiskan satu kelompok dari kelompok lain untuk menjamin adanya satu identitas yang tetap terpisah dari dan berbeda dengan identitas yang lain.

Di Indonesia, metafora pagar (diferensiasi) dan jembatan (sosialisasi) paling mudah terlihat dalam polemik diseputar "jilbab". Polemik ini makin mengemuka di tahun 1989 ketika sejumlah siswi SMAN di Surabaya, Bandung, dan Jakarta diskorsing dan dilarang mengenakan jilbab karena dianggap melanggar disiplin sekolah yang telah ditetapkan "dari atas", yaitu dari Departemen Pendidikan dan Kebudayaan (Ismail, 1999:132-134). Bagi penyelenggara pendidikan, yaitu pemerintah bahwa jilbab dianggap bagian dari politik diferensiasi yang membahayakan keutuhan Negara Kesatuan Republik Indonesia (NKRI) yang majemuk. Sementara, bagi pengkritik kebijakan pemerintah yang melarang jilbab, tindakan pelarangan tersebut dianggap bentuk intervensi negara pada urusan privat agama. Bagi para pendukung jilbabisasi, pemakaian jilbab merupakan bentuk menjalankan kewajiban agama seperti yang disebutkan dalam Surah 33:59. Dari perspektif jembatan (sosialisasi), jilbab menjadi bagian dari politik identitas yang menyatukan sesama mereka yang mengenakannya, sekaligus membedakan atau memisahkan dengan mereka yang tidak memakai jilbab. Ada politik pemisahan agama berdasarkan fashion dan pakaian, tetapi juga ada politik penyatuan agama di antara para pemakai fashion jilbab. Ketika fase kooptasi negara atas Islam berakhir dan diganti oleh fase akomodasi atau "bulan madu" antara Islam dan negara, proyek jilbabisasi semakin masif terjadi dan politik diferensiasi serta sosialisasi di sisi lain pun kian diterima sebagai sesuatu yang alamiah. Inilah yang oleh pengamat disebut sebagai akomodasi di jalur kultural yang makin mematangkan Islamisasi Indonesia (Effendy, 1998:306-310).

Fashion dan pakaian juga mengekspresikan ide-ide, keyakinan, dan nilai-nilai kelompok yang tidak jarang digunakan untuk menantang keyakinan, nilai-nilai, ide-ide, dan pengalaman-pengalaman kelompok lain. Fashion dan pakaian bersentuhan dengan relasi ideologi. Ideologi dapat dirumuskan sebagai serangkaian keyakinan, nilai-nilai, dan ide-ide tentang dunia dan segala sesuatu di dalamnya yang menjadi karakteristik atau kekhasan suatu kelompok sosial" (Barnard, 2001:58). Fashion dan pakaian digunakan sebagai senjata dan pertahanan di mana dengan cara itu ideologiideologi yang dianut kelompok-kelompok sosial diekspresikan dan dapat menentang ideologi-ideologi kelompok-kelompok lain dalam tatanan sosial. Jadi, fashion dan pakaian adalah ideologis dalam artian fashion dan pakaian pun merupakan bagian dari proses yang di dalamnya kelompok-kelompok sosial membangun, menopang, dan mereproduksi posisi kekuasaan, serta relasi dominasi dan didominasi. Dengan begitu, fashion dan pakaian merupakan cara bagi pembuatan ketimpangan status sosial dan ekonomi yang seolah-olah benar dan absah, sehingga bisa diterima, bukan 
hanya oleh orang yang berada dalam posisi dominan, melainkan juga bagi orang-orang yang berada dalam posisi didominasi. Inilah gambaran dari apa yang disebut "hegemoni" (Barnard, 2001:59).

Di Indonesia, khususnya di Jawa, diskursus Santri, Priyayi, dan Abangan yang berasal dari Cliffort Geertz turut membingkai konflik diseputar ideologi dengan resonansinya menyentuh pada remeh-temeh fashion dan pakaian (Woodward, 2012:2-3). Santri merupakan kalangan muslim ortodoks; priyayi adalah kalangan bangsawan yang dipengaruhi terutama oleh tradisi-tradisi Hindu-Jawa; dan abangan adalah masyarakat desa pemeluk animisme. Telah banyak penelitian membantah ketiga varian rumusan Geertz itu. Abangansantri dianggap dikotomi yang sah, tetapi tidak untuk varian priyayi. Varian priyayi banyak dipandang sebagai status daripada sebuah kategori keagamaan karena priyayi dapat masuk ke dalam varian abangan atau santri. Akan tetapi, relasi ideologis turut mendekatkan orientasi abangan dan priyayi dalam satu kesatuan yang berhadapan dengan orientasi santri. Dan untuk kepentingan tulisan ini, kesatuan antara abangan dan priyayi terlembagakan antara lain dalam fashion dan pakaian: parlente, necis, jas dan dasi, dengan latar belakang pendidikan sekuler Barat, berhadapan dengan santri yang identik dengan kekolotan, berpendidikan rendah, kampungan, atau yang sering disebut sebagai "kaum sarungan" (Ja'far, 2009).

Dalam konteks ideologis, fashion dan pakaian juga dipergunakan untuk membuat perbedaan dan status yang ada di antara kelas-kelas rendah dan tinggi yang muncul sebagai legitimasi dan kepatuhan. Kelas bawah membangun jembatan dengan mengenakan katun corak seperti orang yang secara sosial berasal dari kalangan atas, dan kelas atas menanggapinya dengan membangun pagar, dengan mengenakan katun putih biasa yang berbeda dengan katun yang dipakai orang dari kelas sosial yang ada di bawahnya. Hal ini menunjukkan dengan sangat jelas bagaimana kalangan kelas atas mati-matian mempertahankan status yang lebih tinggi mereka lewat sarana fashion dan pakaian (Barnard, 2001:61; Detweiler dan Taylor, 2003:221-222,225). Contoh paling jelas adalah punk. Melalui tampilan yang bisa dilihat dalam rambut lancip tinggi ke atas, kalung rantai, tas gombrang, pakaian rongsokan dan murahan, terbangun ideologi perlawanan terhadap nilainilai kemapanan (berasal dari politics of boredom, politik kebosanan) dan estetis dari kelas-kelas dominan, bahkan serangan ideologis terhadap kapitalisme itu sendiri (Barnard, 2001:61-62; Detweiler dan Taylor, 2003:229-230). Dalam konteks punk, fashion dan pakaian digunakan sebagai senjata ideologis dalam perjuangan kelas melawan ideologi lain. Fenomena punk juga menyuguhkan konsepsi alternatif tentang apa yang disebut cantik atau kecantikan, gagah atau tampan, yang ternyata dibangun oleh konsensus sosial, termasuk mereka yang melawannya dengan mengajukan alternatif lain, "cantik itu luka", kata Eka Kurniawan (Kurniawan, 2006). Ternyata putih, bersih, dan cantik pun sebuah konsensus, kata Ayu Saraswati (Saraswati, 2017). Definisi-definisi tersebut sudah mapan, menjadi mitos dan sarat dengan ideologi warisan kolonial, yang selalu dilawan dengan munculnya definisi baru tentang apa itu cantik atau apa itu keindahan (Budiman, 2002:215-216).

Akhirnya, catatan Idi S. Ibrahim ini penting dituliskan, bahwa sejarah fashion adalah sejarah golongan kaya memerintah buruh miskin (Ibrahim dalam Barnard, 2001; Ibrahim dalam Chaney, 2002:16-17). Demi gaya dan penampilan (tampangisme atau wajahisme, lookism/faceism) kaum aristokrat dan borjuis di masa lalu dan dalam beberapa hal masih hidup di masa kini, tak jarang buruh dibayar murah, tenaganya diperas, nasibnya tidak diperhatikan, masa depannya suram, justru berada di balik pusaran industri mode atau fashion yang gemerlap dan kemewahan gaya hidup segelintir kaum dandy yang necis.

\section{Sumbangan Teologi Moral}

Perspektif teologi moral adalah perspektif kritis yang menjelaskan bahwa tindakan atau gerakan yang secara konsisten memperjuangkan nilai-nilai kebaikan dan 
berdampak baik secara luas disebut sebagai tindakan berkeutamaan (Chang, 2002:15). Daya kritis dalam teologi moral adalah sumbangan kritik ideologi yang menjadi pisau analisis atas konteks untuk menguak apa yang tersembunyi dalam simbol, tanda, dan tindakan. Tujuan dari kritik ideologi adalah menguak dimensi pembebasan, bahwa dunia fashion adalah ladang bagi karya misi dan dialog di tengah "dunia gaya" atau "masyarakat pesolek" (dandy society), sekaligus tugas menemukan wajah dan kehadiran Allah di dalam gegap gempitanya dunia fashion tersebut.

Orang yang bergelut dengan persoalan kritik ideologi adalah Paul Ricoeur. Ia menyumbang tidak hanya rekonstruksi atau rehabilitasi atas makna yang tersebar di dalam simbol dan tanda, melainkan kecurigaan atas makna. Sehingga hermeneutik menjadi praktik kecurigaan atau disebut kritik ideologi (Hardiman, 2015:262-265). Dalam upayanya melakukan kritik, Ricoeur menempuh "belokan bahasa" (linguistic turn). Sebab, di dalam bahasa, subjek atau ego yang dalam filsafat Barat menjadi masalah lahirnya segala bentuk dominasi memperlihatkan aktualisasi yang paling jelas. Di dalam bahasa, terbangun relasi intersubjektif yang berfungsi ganda, yaitu membebaskan dan mendominasi. Relasi membebaskan terjadi ketika bahasa dipakai oleh subjek untuk tujuan-tujuan kebaikan, keadilan, dan menghargai perbedaan. Sebaliknya, relasi mendominasi terbangun ketika bahasa dipakai oleh subjek untuk tujuan-tujuan menaklukkan, menindas, dan mengeksploitasi.

Bahasa adalah teks, demikian kata Ricoeur (Hoed, 2008:106-107). Teks di sini tidak hanya berupa tulisan, walaupun Ricoeur pertamatama memaksudkannya sebagai tulisan. Teks dalam hal ini adalah tindakan manusia. Perluasaan analisis teks kepada tindakan manusia terjadi karena tindakan itu sendiri merupakan rujukan dari banyak teks. Tindakan manusia mencakup berbagai hal apa saja yang dilakukan manusia termasuk yang berasal dari kebudayaan konsumen dengan produknya fashion dan artefak-artefak budaya populer lainnya. Terhadap artefak budaya populer, yaitu fashion, diberlakukan tindakan kritis melalui kritik ideologi. Tujuan dari kritik ideologi atas fashion adalah memperluas makna yang tidak tunggal, melainkan polisemi atau poliponik. Semakin makna itu tidak tunggal (surplus of meaning), semakin terbuka kemungkinan untuk lahirnya jarak yang penting bagi tindakan kritis. Dalam dialog Ricoeur dengan para pemikir post-strukturalisme seperti Derrida, Ricoeur menerima istilah penting Derrida, yaitu dekonstruksi, dengan menunda, dengan tidak terburu-buru membuat makna (Haryatmoko dalam Hoed, 2008; Hoed, 2008:27-31,104-107). Dengan menunda makna (hubungan antara ekspresi teks atau penanda dan unsur isi teks atau pertanda), maka kita tidak mudah jatuh pada klaim-klaim kebenaran atas sebuah makna. Menunda makna adalah sebuah sikap berjarak terhadap serbuan makna yang datang dari realitas virtual (virtual reality) atau dari gempuran budaya citra (image culture). Tantangan yang datang dari hiper-realitas ini hanya dapat diantisipasi untuk "sementara" dengan sikap kritis.

Dari perspektif teologi moral, maka kritik ideologi akan melahirkan dua sikap keutamaan. Di sini pemikiran Frans MagnisSuseno tentang otentisitas dan A. Setyo Wibowo tentang Sophrosune (keugaharian-mawas diri) akan sangat membantu. Pertama, tentang ottentisitas (Magnis-Suseno, 2001:12-17). Kata "autentik" (dari bahasa Yunani "authentes" = penyebab / author) mau mengatakan bahwa seseorang membawa diri bukan sebagaimana ia diharapkan oleh lingkungan sosialnya, tidak begitu saja menyesuaikan diri dengan segala budaya, pola sikap, dan kelakuan yang diharapkan oleh masyarakatnya, melainkan menurut keasliannya, menurut bagaimana ia sebenarnya. Orang dinamakan autentik apabila ia membawa diri sebagai dirinya sendiri, bukan sebagai orang jiplakan, orang tiruan, orangorangan yang hanya dapat membeo yang tidak mempunyai sikap dan pendirian sendiri karena ia dalam segala-galanya mengikuti mode, budaya citra, fashion bahkan masyarakat pesolek (dandy society), atau pendapat umum yang berasal dari budaya massa dan arah angin. 
Dalam masyarakat konsumtif bahwa jargonnya adalah "kamu bergaya maka kamu ada", maka yang terjadi adalah "komunikasi melalui penampakan luar menjadi dominan" (Chaney, 2002:177). Orang tidak lagi mementingkan isi, tetapi penampilan. Orang mati-matian mempertahankan penampilan dengan harga berapa pun, demi tetap tidak kehilangan momentum yang disebut "hidup bergaya". Pencitraan lalu menjadi tujuan untuk hidup. Di sinilah orang disebut tidak hidup autentik, tetapi hidup dalam dunia simulacra, dunia tiruan, jiplakan, dan membeo pada semua yang dianggap kenikmatan. Dalam rangka kritik ideologi, maka menjadi autentik berarti kemampuan menggambarkan tentang diri sendiri secara kritis tanpa dibuat-buat apalagi demi sebuah kepalsuan.

Frans Magnis-Suseno optimis bahwa autentik itu dapat diwujudkan dan dipertahankan. Kita autentik karena kita menghayati diri sendiri (cita-cita dan nilai-nilai yang dianut) apa yang dicintai, dihargai, dicita-citakan, begitu pula apa yang dibenci dan ditolaknya. Dalam kaitan ini, ritual keagamaan tidak perlu tergeser menjadi religiotainment, yang rela mengorbankan nilai-nilai moral dan spiritual demi daya tarik. Lawan dari menjadi menarik atau bergaya adalah Allah yang menjadi manusia yang tidak menarik. Itulah makna yang terkandung dalam teologi inkarnasi. "Allah yang tidak menarik" (Wijaya, 2017:1011) adalah kritik keras terhadap budaya yang mengumbar syahwat hedonisme. Dalam dialog dengan budaya termasuk budaya populer, maka otentisitas penting agar tidak bercitacita palsu karena mudah menjiplak atau meniru yang bukan merupakan gambaran dirinya sendiri. Dengan bersikap kritis dengan tidak asal ikut segala pandangan yang berasal dari lingkungan yang sudah direkayasa oleh pencitraan.

Kedua, sophrosune adalah salah satu keutamaan pokok (cardinal virtues) sebagai kritik atas hidup bermewah-mewahan dan buas dengan tuntutan mawas diri serta pengenalan diri (Wibowo, 2013:14-16). Kata Yunani, sophrosune, artinya keugaharian, secara eksternal menggambarkan perilaku hidup lembut, tenang, sahaja, ugahari (artinya sedang, sederhana). Sophrosune yang berarti kesederhanan, muncul sebagai hasil pengekangan, pengendalian, dan pengaturan. Maka, kesahajaan merupakan karakter seseorang yang tahu batas, tahu menahan diri, tahu mengekang nafsu, sehingga memiliki ketahanan hati dan tidak jatuh dalam perilaku ekstrem atau berlebih-lebihan. Lebih dari itu, sophrosune adalah keutamaan serba pantas yang tampak dalam shame culture (budaya tahu malu).

Dalam konteks budaya dominan saat ini, yaitu "hidup untuk gaya" melalui sifat konsumtif dan pencitraan, sophrosune menjadi relevan dijadikan gaya hidup. Sophrosune sekaligus menjadi nilai diri yang perlu diperjuangkan agar kita tidak terbawa arus atau terombang-ambing dalam pusaran budaya populer yang tidak selamanya positif. Perlu menahan diri dan mengekang nafsu dari gempuran artefak-artefak budaya populer yang ditampilkan oleh media sosial, mulai dari iklan gaya hidup, hingga bujuk rayu aneka hiburan melalui ilusi-ilusi tentang diri (illusion of self). Ketika gaya menjadi segala-galanya dan segala-galanya adalah gaya, maka hedonisme menjadi ukuran dan mendominasi persepsi manusia, pikiran, dan perilaku.

Nilai yang tumbuh dari spiritualitas sophrosune (ugahari) rasanya juga sejalan dengan usaha manusia mengonstruksi suatu teologi seksualitas yang diperbaharui (Detweiler dan Taylor, 2003:236), yaitu teologi tentang nilai tubuh. Berbeda dengan kebudayaan konsumtif yang menempatkan tubuh sebagai wahana kenikmatan karena orang berlomba-lomba untuk memodifikasi tubuh demi mengumbar seksualitas, maka teologi tubuh itu menjadi interior freedom (telanjang itu lepas bebas). Bebas dari ketakutan karena dosa. Ketelanjangan adalah kemurnian tubuh sebagai tanda yang menunjuk pada misteri Ilahi. Paus Yohanes Paulus II memaksudkan teologi tubuh melampaui organisme biologis, tetapi sebagai sebuah subjek teologis. Maksudnya, tubuh ini menjadi tanda dan sarana menyingkap misteri Ilahi (Prihartana, 2010:4-23). Oleh karena itu, responnya adalah menjaga tubuh untuk tidak 
menjadikannya sekadar sarana pencitraan, seperti yang tumpah-ruah di dalam artefakartefak budaya populer.

Mengenai fashion kaum rohaniwan seperti yang tampak pada toga dan jubah masih menjadi kontroversi. Diantara kontroversi tentang pakaian khas rohaniwan, ukurannya tetaplah prinsip otentisitas yang terkait nilainilai yang diusung. Di dalam fashion tersebut, bukanlah pencitraan yang mau diusung, melainkan nilai keugaharian (sophrosune) dan fashion-ku sebagai tanda yang menyingkap misteri Ilahi. Fashion tersebut menjadi kesaksian tentang kesederhanaan hidup atau kesahajaan perilaku yang menahan nafsu dan keglamoran budaya populer. Moralitas pakaian rohaniwan sesungguhnya terletak pada nilai yang diperjuangkan oleh sub-kultur tertentu (agama/gereja) yang berhadapan dengan arus postmodernisme yang salah satunya menghempas masyarakat agama.

Berdialog dengan dunia masa kini diyakini sebagai salah satu panggilan gereja. Kehadiran gereja di dunia fashion dapat dipahami sebagai wujud misi yang kontekstual. Dalam responnya atas salah satu artefak budaya populer, yaitu dunia digital, Paus Fransiskus mengingatkan: "Janganlah segansegan menjadi warga dunia digital. Sangatlah penting perhatian dan kehadiran gereja dalam dunia komunikasi untuk berdialog dengan manusia masa kini untuk mengantar dia berjumpa dengan Kristus" (Pancani, 2014). Akan tetapi, ajakan Paus Fransiskus tersebut tidak menutupi kenyataan bahwa dunia hari ini berbeda dengan kemarin. Oleh karena itu, dibutuhkan cara memahami secara berbeda dan kritis melalui sebuah hermeneutik kritis yang disebut juga kritik ideologi. Seperti dijelaskan sebelumnya, teologi moral yang mengusung fungsi kritis adalah teologi moral yang hendak menguak nilai-nilai keutamaan untuk menjadi praksis iman di tengah konteks budaya populer, yaitu otentisitas diri dan sophrosune (keugaharian).

Pada hakikatnya, tugas panggilan umat Kristiani adalah membawa kabar baik bagi setiap orang dalam konteks budayanya. Secara spiritual, hal itu berarti memfasilitasi perjumpaan dengan Tuhan di tengah aktivitas sehari-hari yang dipengaruhi nilai-nilai sosialkultural tertentu. Tugas ini hanya mungkin dilakukan bila umat sendiri mempunyai nilai hidup, yaitu nilai-nilai yang diperjuangkan, seperti nilai-nilai keutamaan otentisitas diri dan keugaharian. Dalam terminologi teologi Kristiani, nilai-nilai ini dapat disebut pula sebagai nilai-nilai Kerajaan Allah, yaitu Kerajaan milik Allah yang tidak menarik dan yang tangguh melawan budaya hedonis. Dalam nilai-nilai yang seperti itulah wajah Allah digambarkan dan keprihatinan-Nya diwartakan bagi manusia.

\section{SIMPULAN}

Teologi mengenai fashion harusnya menjadi suatu konstruksi tentang cinta, kebebasan, dan kemurnian sebagai ekspresiekspresi yang jauh lebih baik ketimbang dominasi, kekerasan, terorisme, dan bentukbentuk fundamentalisme. Manusia hidup di suatu masa di mana pencitraan dan ritual-ritual religius telah diubah menjadi pilihan-pilihan gaya hidup. Madonna dan sejumlah artis hip-hop tidak jarang terlihat dengan aksesoriaksesori berbentuk salib. Para rapper tampak gembira dalam memamerkan perhiasan platinum yang besar dari intan dan salib sebagai simbol-simbol pilihan mereka. Simbol salib barangkali membuat para selebriti merasa aman dan terlindung. Kemudia yang ditolak hanyalah agama terlembaga yang mengelilingi Kristus dan salibnya dalam tabu-tabu. Akan tetapi, bukan berarti yang spiritual menjadi hilang dan yang sedang terjadi adalah apa yang sudah mapan sedang didefinisikan ulang.

Kemapanan yang digugat itu secara fashion diwakili oleh jubah-jubah para rohaniwan yang paling tidak di kalangan Protestan di Indonesia, semakin lama semakin elitis, eksklusif, dan tertutup demi menyatakan kemapanan. Jadi kekristenan yang sudah melembaga itu ditantang untuk mendefiniskan ulang makna kehadirannya dengan dimulai dari tampilan fashion-nya untuk menjadi semakin populis dan cair dengan berbagai masukan yang datang dari budaya populer. Sebagaimana Tuhan tidak 
pernah selesai didefinisikan, pendefinisian teologi fashion pun belum selesai.

\section{DAFTAR PUSTAKA}

Adhi, P.N. 2012. Pergulatan Katekese dengan Budaya Pop: Sebuah Catatan Singkat Pengalaman Mewarta di Era Xer, Virtual dan Konvergensi Media. Dalam Pewartaan di Zaman Global. Editor B.A. Rukiyanto. Yogyakarta: Kanisius.

Baran, Z., dan E. Tuohy. 2011. Citizen Islam: The Future of Muslim Integration in the West. New York: Continuum.

Barnard, M. 2001. Fashion sebagai Komunikasi: Cara Mengomunikasikan Identitas Sosial, Seksual dan Gender. Yogyakarta: Jalasutra.

Baudrillard, J. 1992. Selected Writings. Editor Mark Poster. Cambridge: Polity Press.

Budiman, H. 2002. Lubang Hitam Kebudayaan. Yogyakarta: Kanisius.

Chaney, D. 2002. Lifestyles: Sebuah Pengantar Komprehensif. Yogyakarta: Jalasutra.

Chang, W. 2002. Menggali Butir-Butir Keutamaan. Yogyakarta: Kanisius.

Detweiler, C., dan B. Taylor. 2003. A Matrix of Meanings: Finding God in Pop Culture. Michigan: Baker Academic.

Effendy, B.1998. Islam dan Negara: Transformasi Pemikiran dan Praktik Politik Islam di Indonesia. Jakarta: Paramadina.

Hardiman, F.B. 2015. Seni Memahami: Hermeneutik dari Schleiermacher sampai Derrida. Yogyakarta: Kanisius.

Haryatmoko. 2016. Membongkar Rezim Kepastian: Pemikiran Kritis PostStrukturalis. Yogyakarta: Kanisius.

Hoed, B.H. 2008. Semiotik E Dinamika Sosial Budaya. Depok: Komunitas Bambu.

Horell, H.D. 2003. Cultural Postmodernity and Christian Faith Formation. Dalam Horizons and Hope: The Future of Religious Education. Editor T.H.
Groome dan H.D. Horell. New York: Paulist Press.

Ibrahim, I.S. 2011. Kritik Budaya Komunikasi: Budaya, Media dan Gaya Hidup dalam Proses Demokratisasi di Indonesia. Yogyakarta: Jalasutra.

. 2002. Kamu Bergaya Maka Kamu Ada!": Masyarakat Pesolek dan Ladang Persemaian Gaya Hidup. Dalam Lifestyles: Sebuah Pengantar Komprehensif. Editor D. Chaney. Yogyakarta: Jalasutra.

2001. Pakaian Anda Menunjukkan Siapa Anda? Semiotika Fashion dan Pakaian sebagai Komunikasi Artifaktual. Dalam Fashion sebagai Komunikasi: Cara Mengomunikasikan Identitas Sosial, Seksual dan Gender. Editor M. Barnard. Yogyakarta: Jalasutra.

Ismail, F. 1999. Ideologi Hegemoni dan Otoritas Agama: Wacana Ketegangan Kreatif Islam dan Pancasila. Yogyakarta: Tiara Wacana.

Ja'far, S. 2009. Pasang Surut Politik Kaum Sarungan. Yogyakarta: Kanisius dan Impulse.

Kurniawan, E. 2006. Cantik Itu Luka: Sebuah Novel. Jakarta: Gramedia.

Magnis-Suseno, F. 2011. Otentisitas dan Perkembangan Budaya. Basis, (50):1217.

Marsh, C., dan V.S. Roberts. 2012. Personal Jesus: How Popular Music Shapes Our Souls. Michigan: Baker Academic.

Pancani. P. O. 2014. “Pesan Paus Fransiskus Untuk Hari Komunikasi Sedunia Ke48 - 1 Juni 2014." Paroki Santo Paulus. Diakses pada tanggal 7 September 2017. <https://santopauluspku. wordpress.com/2014/03/19/ pesan-paus-fransiskus-untukhari-komunikasi-sedunia-ke-48-1juni-2014/>. 
Prihartana, A. 2010. Teologi Tubuh: Refleksi dari Yohanes Paulus II. Info Gender, 51 (15):4-23.

Purwatma, M. 2016. Internet dan Pewartaan dalam Pesan Paus untuk Hari Komunikasi Sedunia 2002-2016. Orientasi Baru, 25 (01):57-73.

Ricoeur, P. 1970. Freud and Philosophy: An Essay on Interpretation. Terjemahan Denis Savage. New Haven: Yale University Press.

Saraswati, L.A. 2017. Putih: Warna Kulit, Ras, dan Kecantikan di Indonesia Transnasional. Serpong: Marjin Kiri.

Scheuerer, F.X. 2001. Interculturality: A Challenge for the Mission of the Church. Bangalore: Asian Trading Corporation.

Schreiter, R.J. 1998. The New Catholicity: Theology between the Global and the Local. New York: Orbis Books.

Shields, R. 2011. Virtual: Sebuah Pengantar Komprehensif. Yogyakarta: Jalasutra.

Singgih, E.G. 2017. Keluar dari Dunia Maya, Masuk ke Dunia yang Sebenarnya: Spiritualitas untuk Masa Kini di
Indonesia. Makalah Kuliah. Teologi, Spiritualitas dan Seni. Yogyakarta: Pascasarjana Ilmu Teologi UKDW.

Storey, J. 2010. Cultural Studies dan Kajian Budaya Pop: Pengantar Komprehensif Teori dan Metode. Yogyakarta: Jalasutra.

Strinati, D. 2004. An Introduction to Theories of Popular Culture. London: Routledge.

Sugiharto, I.B. 1997. Postmodernisme: Tantangan bagi Filsafat. Yogyakarta: Kanisius.

The Voice of Italy. 2014. “The Voice IT | Serie 2 | Blind 2 | Suor Cristina Scuccia - \#TEAMJ-AX." Video Youtube. Diakses pada tanggal 7 September 2017. <https://www.youtube.com/

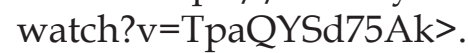

Wibowo, A.S. 2013. Sophrosune: KeugaharianMawas Diri. Basis, (62):14-16.

Wijaya, Y. 2017. Tertarik kepada Tuhan yang Tidak Menarik: Memaknai Teologi Inkarnasi dalam Hidup Sehari-hari. Jakarta: Grafika KreasIndo.

Woodward, M.R. 2012. Islam Jawa: Kesalehan Normatif versus Kebatinan. Yogyakarta: LKiS. 